\title{
GIANNUZZI Y EL TRABAJO CON LAS RUINAS. ENTRE LA INSIGNIFICANCIA Y LA ARCHISIGNIFICANCIA DE LO QUE HAY
}

\author{
Franca Maccioni \\ IDH-CONICET, Universidad Nacional de Córdoba \\ Córdoba, Argentina \\ franca.maccioni@gmail.com
}

\begin{abstract}
RESUMEN / ABSTRACT
En este trabajo proponemos recorrer la obra poética completa de Joaquín O. Giannuzzi en un intento por explorar cuál es la relación que esta escritura sostiene con los restos y las ruinas de los grandes operadores de sentido de su tiempo (la Historia, el sujeto, la técnica, el mundo, el sentido mismo). Allí donde lo que parece primar es una relación anonadante con los escombros de una civilización y sus proyectos, intentaremos pensar qué otras praxis de sentido se afirman en su poética, es decir, en qué medida la escritura poética permite abrir otro modo de relación con los restos.
\end{abstract}

PALABRAS ClaVE: Giannuzzi, fin del sentido, ruinas, recomienzo, poesía argentina contemporánea.

\section{GIANNUZZI AND HIS WORK WITH THE RUINS. BETWEEN THE INSIGNIFICANCE} AND THE ARCHISIGNIFICANCE OF WHAT THERE IS

In this article, we aim to survey the poetic writing of Joaquin O. Giannuzzi in an attempt to explore what is the relationship that this writing sustains with the remains and ruins of the great sense operators of his time (History, subject, technique, the world, the meaning itself). Where what seems to prevail is an tragic relationship with the rubbles of a civilization and its projects, we will try to think what other praxis of meaning can be found in its poetics, that is, we will try to explore to what extent poetic writing allows to open another meaningful mode of relationship with the remains.

KEYWORDS: Giannuzzi, end of meaning, ruins, rebeginning, contemporary Argentinian poetry. 
En 1962, Giannuzzi publica el libro Contemporáneo del mundo y acierta, con su título, a dar con una clave de lectura (im)posible en la que se juega quizás todo su proyecto de escritura. Su poética nos lega la tarea y la urgencia de ser contemporáneos del mundo, al tiempo que expone con crudeza la incertidumbre que subyace en ambos términos: en su escritura, el mundo pende sobre lo inmundo y las medidas que se supone deberían aferrarlo a su tiempo parecen girar sobre el vacío. A lo largo de su obra completa, lo que encontramos es un mundo y una historia que han perdido todo sentido en la absurda acumulación de la violencia. Y allí donde las promesas de la historia se revirtieron en catástrofes, es el pensamiento (poético) mismo el que se revela impotente para aferrar el tiempo (para dar sentido a su curso y actuar sobre él) y para abrir un mundo, es decir, un espacio-tiempo compartido y con sentido.

Sin embargo, es de cara a esa crisis (al desarraigo del sentido, a la precariedad que abre la falta de fundamentos) que Giannuzzi instala su trabajo y la apuesta de su escritura: encontrar un modo de ser contemporáneo ${ }^{1}$ de este mundo sabiendo que en el lugar de los operadores de sentido que garantizaban $a$ priori esta relación hoy no hallamos más que ruinas o restos. Desde allí, "en los bordes del cráter" - para recuperar la imagen que Masiello² propone para

\footnotetext{
Acuñamos este término para pensar desde él una relación problemática con el tiempo y la historia que surge cuando constatamos la ruina de toda medida a priori que garantice una pertenencia sensata entre el tiempo y los existentes. Desde que estamos expuestos a una errancia del sentido, lo contemporáneo deberá en adelante ser performado, es decir que se abre como tarea por hacer. Tarea que demanda imaginar otros modos de figurar la temporalidad; modos en el que no se posponga (teleológicamente) el sentido a la dimensión de una totalidad que nunca llega y que impugne también la imaginación del tiempo como continuum de instantes progresivos e inextensos. Siguiendo los aportes de Agamben $(2007,2011)$ y de Nancy $(2003$, 2014), la posibilidad de llegar a ser contemporáneos, dependerá de la posibilidad de figurar un tiempo interrumpido, adecuado a la acción y a la decisión, y una experiencia de la historia capaz también de producir una relación intempestiva respecto de la época para así poder recomenzar una experiencia práctica de la historicidad allí donde ésta se expone como clausurada. Ambos pensadores coinciden en que llegar a ser contemporáneos depende de la posibilidad de poder exponer un estar en común, de poder ficcionalizar un modo posible de existir juntos, es decir, un mundo. Performar un espacio-tiempo contemporáneo y en este sentido, un mundo, supone siempre también disputar el modo en que este se escenifica de hecho (como inmundo).

En el artículo "En los bordes del cráter (sobre la generación del 90 en Argentina)", Masiello (81) propone la imagen del "cráter" para pensar diversas producciones literarias
} 
pensar la literatura contemporánea- Giannuzzi (70) interpela a la poesía y la convoca a recomenzar la tarea: "Este mundo, muchachos, ¿no lo oyen?/ reclama otra especie de poesía".

La propuesta de este artículo, entonces, es recorrer esta poética intentando auscultar el doble movimiento que insiste, al mismo tiempo, en constatar las ruinas del conjunto de los operadores que tramaban otrora el sentido de la existencia y sus prácticas (la historia, la literatura, el mundo, la experiencia, hasta el sentido mismo) e imaginar formas posibles de reactivar otros modos de producción del sentido (y de esos sentidos) sin desconocer los alcances de este diagnóstico; es decir de ensayar modos de recomenzar otras relaciones posibles con el mundo, la historia y la poesía misma.

Como dijera Lamborghini (Cit. en Fondebrider 234), "testigo lúcido de nuestro tiempo", la "mirada escéptica" de Giannuzzi escribe "el fracaso de toda una cultura sospechada de barbarie". En este paisaje desencantado, "desastre", "estupor", "perplejidad" signan el pathos de toda su poética haciendo de ésta un testimonio ejemplar de la crisis radical del pensamiento y del mundo. Sin embargo, en el umbral de la crisis en la que este poeta escribe sabiendo que "la duda es inmensa y pone a todas las cosas en un estado de alta improbabilidad" (Didi-Huberman 27), los casi cincuenta años de escritura ininterrumpida dan cuenta de la inmensidad de la tarea de este poeta: llegar a ser contemporáneo de un mundo que parece hurtarse a la razón y devolverle tan solo la imagen

(narrativas y poéticas) en la ambivalencia de la experiencia democrática o de la "post-transición" como "efervescencia al borde del caos". Recuperando los aportes de Blanchot sobre una literatura del desastre y de Badiou sobre el "evento", la autora recorre ciertas zonas de la literatura contemporánea tensionando su singularidad con un diagnóstico amplio ("el colapso de las izquierdas, las consecuencias del 11 de septiembre [...], la crisis de gobernabilidad que asedia hoy a los estados nacionales [...], la debacle argentina de 2001 y sus efectos a posteriori") que ha llevado a artistas y escritores a "producir una indagación sobre las catástrofes de nuestro tiempo". En una línea similar a la que aquí proponemos, Massiello (82) afirma que: "estamos ante una literatura que trabaja con las sobras, con la basura de la metrópoli y los desgastes de una civilización en ruinas, donde casi siempre se enfatiza la repetición de lo inconsecuente [...]. En estos casos, nadie puede hablar de verdades absolutas ni de posturas éticas apropiadas, así como tampoco aferrarse con firmeza a esos hilos de la historia que necesitamos para mantenernos enteros". 
invertida, catastrófica, de una racionalidad técnica que precipita toda existencia en algo "peor que la desgracia misma: un atontamiento, un extravío, un estupor sin recursos" (Nancy, L'Équivalence 27).

A los ojos de Giannuzzi, el mundo se expone como "una usura abstracta/ que amenaza con pérdida permanente./ [...]/ De manera que resta/ de todo ese estupor que no puede/ soslayarse, el dinero/ entre las manos pálidas de marido y mujer,/ Jesucristo y sus enfermas garantías/ y la Revolución, esa constante profecía/ de la lógica y el asco de nuestro tiempo" (119). Como testigo implacable de un mundo en el que naufragan las certezas y el valor singular de la existencia, Giannuzzi traza en su escritura el devenir "zona bancaria" del mundo en el que Dios parece haber cedido su lugar al capital como único centro de valoración unitaria de lo que hay: "la cruda misión de la materia/ silba en la zona del oro./ La divinidad está aquí por una especie/ de delegación sombría” (292).

Ya sin trascendencia, sin profecías utópicas ni religiosas, Giannuzzi escribe "con la conciencia exasperada de estar viviendo en un mundo que perdió la gracia: el cuerpo decae, la sociedad es una gran máquina impasible, la historia resultó una sarta de promesas incumplidas, la inteligencia humana sufre la infelicidad de ser demasiado consciente de sí" (Freidemberg, Cit. en Fondebrider 60). En este mundo devenido inmundo, la única lógica que aún parece imperar es la de la equivalencia general ${ }^{3}$ que encuentra su imagen ejemplar en el "tacho de basura": esa fosa común en la que la cultura acumula las ruinas de su pasado vencido y caduco y expone en el presente su rechazo a la vida.

En "Basuras al amanecer" se lee: "Comprobé que las cosas no mueren sino que son asesinadas. [...] Parece que la cultura consiste/ en martirizar a fondo la materia y empujarla/ a lo largo de un intestino implacable" (143). Y

Es Jean-Luc Nancy quien en L'Équivalence des catastrophes piensa, desde la noción de "equivalencia general", el devenir inmundo del mundo ante el triunfo nihilizante del capitalismo global. Según sus términos es la lógica de la equivalencia general de la mercancía y el capital, es decir, el modo cómo el valor moneda anula todo otro modo de valoración singular de lo extistente, lo que impide trazar otras relaciones sensatas con el mundo, la historia y el tiempo. En este contexto, su apuesta que, entendemos coincide con la de Giannuzzi, se inclinará por pensar modos de relación entre inconmensurables, e inequivalentes proponiendo un pensamiento del presente, rendido a la existencia singular, a aquello de lo que sería posible estar próximos. Allí se abriría entonces la posibilidad de disputar la condena a la insignificancia de lo existente que este régimen económico supone, en pos de una archisignificancia de lo que hay. 
el diagnóstico se extrema en otro poema que hace de esta imagen, justamente, la imagen de la época. En "Apuntes de época", así se titula, leemos: "La calle, esta mañana,/ sólo ofrecía opciones mortales./ De los edificios descendían/ entre bocanadas de humo y odio/ sufrimiento de hombres, de mujeres y de objetos manufacturados./ Morir sin esperanza era el único credo/ y el mundo terminaba en los tachos de basura./ No era un momento surrealista, pueden creerme" (177).

"Esto sucede". Así se titula, significativamente también, otro de los poemas que inscribe el devenir bancario del mundo en el espacio de la ciudad que, vuelta ahora una mera aglomeración, este poeta, arrojado, degradado, intentará vanamente comprender. Aquello que fue creado por los hombres expone en adelante su desarrollo autónomo a pesar y contra sus creadores que, incomunicados, alienados, con rostros insípidos en los que ya no encontramos ningún atisbo del gusto por la existencia, se sienten arrojados, abyectos en una construcción infernal y contemplan, desde allí, pasivamente un destino que ya no los incluye. Como dijera Mattoni (147) "allí el presente aplasta la memoria, cualquier ademán de estilo se borra con las nuevas construcciones, que a su vez disminuyen el cuerpo de los seres hablantes a la altura de un insecto rodeado de una colmena enigmática, cuya finalidad desconoce".

En esta poética que percibe el presente como una acumulación sin fin de desechos y ruinas, no solo la memoria se verá "aplastada" sino sobre todo la experiencia práctica del tiempo en la que se escurre, para este yo poético, toda posibilidad de sentirse en la historia. Dos extensos poemas de Contemporáneo del mundo (1962), "Progenitores" y "Nosotros", signan, en esta línea, la relación anonadante que este poeta sostiene tanto con el pasado heredado cuanto con la posibilidad de simbolizar un espacio-tiempo compartido, contemporáneo, un mundo, en suma. Al comienzo del poema "Nosotros" leemos:

En la mitad del siglo nuestros huesos cumplieron treinta años y nos correspondió obtener las venenosas conclusiones de la época. Mejor no recordar. A nuestra espalda nos limpiamos la mugre de dos guerras; otros quitaron los escombros de las calles, otros brindaron y bebieron por la muerte la maldición y la culpa de los otros. 


\author{
$[\ldots]$ \\ Hubo otra cosa: en el centro \\ de la posible diversión o la catástrofe \\ en medio del desastre o la eficacia \\ un ademán extraño nos detuvo; \\ esto ocurría en la noche, cuando con estupor \\ mirábamos de pronto entre los dedos \\ como buscando algo que habíamos perdido \\ y no podía recordarse. Allí conjeturábamos \\ una verdad indefensa, un sentido remoto \\ en el fracaso hacia la tumba \\ donde caía la lluvia. Ustedes, \\ jueces de antaño y de mañana, \\ pónganse la peluca, córtense las uñas \\ con prudencia y en orden; aclaren ante todo \\ la razón del malestar que precede a la sentencia \\ y recojan después, si pueden, la victoria \\ de esa verdad secreta: \\ ella justificó estos huesos de posguerra, \\ treinta años cumplidos y ninguna conclusión. \\ (65-68)
}

Para este poeta que, como el Angelus Novus de Klee, solo encuentra escombros en el pasado y perplejidad ante el futuro, la difícil tarea de llegar a ser contemporáneo del mundo deberá medirse en adelante con la constatación de que tanto el mundo cuanto la historia, han perdido todo sentido en la absurda acumulación de la violencia. Ya no es posible sacar conclusiones que justifiquen el osario que resta como legado, ni encontrar un espacio-tiempo de acción sobre la historia: el yo poético se expone, así, como un desheredado de su tiempo al que "ya no le pertenece lo que fue, y lo que será todavía no" (Agamben, Infancia 58).

Ya no hay historia ejemplar, acontecimientos ni héroes que merezcan ser retenidos e imitados. La perplejidad ante la constatación de que la época es "un coordinado funeral, un lento/ camino asegurado hacia la muerte" (69) hace naufragar también cualquier intento de historia en sentido retórico, cualquier representación o relato que pretenda construir una disposición significativa de los hechos y dar razón de ellos. Tan solo resta la historia como un modo específico del tiempo que no nos pertenece, como potencia ontológica, al decir de Rancière (61), "como el destino común que los hombres hacen pero que sólo hacen en la medida en que constantemente se les escapa, constantemente sus promesas se revierten en catástrofes". 
Y ahí estamos "nosotros", entonces, sin compartir más que el entierro de una generación y sus certezas, sabiéndonos continuadores sin plan ni plano de una burla que se perpetúa en la catástrofe: "Hemos perdido el tiempo", afirma. Y este diagnóstico insiste en "Progenitores", donde leemos:

Es muy difícil explicar el mundo

que nos están dejando los que a morir empiezan.

Correspondió a nosotros

partir de la neurosis o el alcohol, como a otros

de la mugre, las bombas, la poesía de vanguardia

o simplemente del vaso de cicuta. Se trataba

de asumir la discontinuidad

en el orden fallido de los otros. Finalmente

jugando al desencanto o a la profecía social

nos hemos puesto graves sin sacar conclusiones.

[...] Ellos

nos legaron un mundo

como librándose de un hierro al rojo

que se deja en la mano del vecino distraído,

una especie de ratería

que entregó en lugar de tomar.

[...]

Una tumba para ellos. Un puñado de tierra

en despedida y acción de gracias.

Ahora es nuestra vuelta pensativa del sepelio:

padres irónicos: ¿qué inocencia nos dejaron

aparte de la música y los dientes,

para intentar la construcción de algo

importante y real? Vacío

en la retórica y el hueso íntimo:

"Sois la nueva era y arreglaos".

Si lo nuestro es mentira que no sea

la estafa de ellos. Si nos toca partir

desde el engaño, desde el hierro al rojo,

ya no es posible simular más tiempo

mirando hacia otra parte,

acariciando el gato o el lenguaje

detrás de los cristales o el alcohol.

Porque si es muy difícil explicar un mundo

que insiste en reclamar nuestra complicidad,

eso no es decisivo: un ademán cargado de sentido, 
es decir, de justicia, importa más

que obtener conclusiones ya sepultas

con la acción de los otros. Una gota de lluvia

cayó sobre su tumba.

Pero si alguno afirma que está solo

frente a su propio perro pues no está papá,

y que no puede dar un paso

sin continuar la peste que heredó,

entonces, que cada uno hable en su nombre

cuando salga del cine o el cementerio,

y diga: Yo, me reconozco en esta fastidiosa historia

soy hijo de la estafa y de los muertos recurrentes,

me ha tocado la usura y tengo tiempo. (74-75)

Una vez más, este poema testimonia el sinsentido de una historia que "se distingue a partir de ahora a través del exceso bruto de lo que ha sido por encima de toda significación" (Rancière 62). Y junto a este fin del sentido de la historia es el fin del sentido en todos los sentidos lo que el poeta experimenta como una crisis radical. Ya no es posible "explicar el mundo", "sacar conclusiones", subsumir en un pensamiento unitario la contradicción y la incoherencia de su "orden fallido". Entre la "diversión o la catástrofe", si hubo algo, escribe, lo hemos perdido y ya no es posible recordarlo; en adelante, solo un gesto cómplice podría afirmar sin náusea ni culpa que este es "nuestro tiempo", que nos "pertenece". "Hemos perdido el tiempo", afirma de nuevo, y, con él, hemos perdido también toda posibilidad de aferrar una oportunidad en el presente.

Como escribiera en "Nuestros días mortales", "oscuro es todo esto", "ninguna luz habrás conseguido traer desde el territorio transcurrido". Al interior de este diagnóstico, este poeta arrojado y desheredado en un mundo y una historia insensata se volverá un total "Desconocido", impotente ante un tiempo que no le pertenece, ante la imposibilidad de actuar sobre él y de abrir un mundo en lo inmundo:

$[\ldots]$

En este útero insípido, en el huevo lavado

de la mente, ninguna

oportunidad para incubar

una semana próxima. Pues todo

repetirá a todo. El horizonte

se ha nivelado. El poeta se ha vuelto 
un fenómeno discontinuo jadeando en un rincón del dormitorio, hurgando en profundidad desde sombríos pulmones, practicando una especialidad que a nadie salva [...]. (298)

Insistamos, entonces, en la pregunta: ¿cómo llega la escritura de Giannuzzi a afirmar otra relación con los restos de este mundo que ha perdido su sentido?, ¿cómo se hace espacio la palabra, el pensamiento de quien siente todo el peso fatídico de una época que no cesa de clausurarse en el ocaso continuo de la muerte?, ¿cómo ser, en suma, contemporáneo de un tiempo expropiado por el sinsentido de la historia y de un mundo que se ha vuelto inmundo? Porque si el mundo se define, como afirma Nancy, por ser ese ordenamiento propre -en francés, a la vez propio y limpio-desde los poemas de Giannuzzi podemos afirmar que:

Ya no hay más mundo: ni más mundus, ni más cosmos, ni más ordenación compuesta y completa en el interior o desde el interior de la cual encontrar lugar, abrigo y las señales de una orientación. Más aún, ya no contamos más con el "aquí abajo" de un mundo que daría paso hacia un más allá del mundo o hacia un otro mundo. No hay más Espíritu del mundo, ni historia para conducir delante de su tribunal. Dicho de otro modo, no hay más sentido del mundo. (Nancy, El sentido 17).

$\mathrm{Al}$ interior de este fin del sentido del mundo en tanto fin del mundo del sentido, en el que se suspende cualquier referencia o destinación capaz de garantizar las significaciones que permiten volverlo sensato, algo queda por pensar en torno a esta experiencia impertinente del tiempo, a esta relación anonadante del pensamiento y el mundo y a este "fenómeno discontinuo" que es el poeta. Como sugiere con cierta ironía otro poema, "Sin duda, el poeta J. O. G./ es el único autor de su miseria/ y no necesita colaboración alguna. [...] / Pero es extraño/ que con tanta materia disponible/ tan rica sustancia con sentido/ este hombre lo confunda todo,/ no sintetiza una oportunidad/ y sólo se le ocurre/ mentir para soportar la vida” (122). “¿Fue inevitable este rostro/ en el melodrama del mundo que toca a su fin?" (340), podemos preguntarnos con él. ¿Qué impide a este poeta "sintetizar una oportunidad", abrir una relación con el mundo, con sus restos, con esa abundante "materia disponible", "sustancia con sentido"? 
La respuesta a esta pregunta no es unívoca. Podemos comenzar hipotetizando que es la pérdida del orden de la racionalidad clásica la que abisma el pensamiento de este poeta en una experiencia anonadante del sentido, de la incoherencia radical en la que naufraga toda posibilidad de acción sobre la historia y de afirmación de un presente. Es la experiencia del fin del sentido, en suma, la que desfonda al sujeto que otrora se garantizaba su señorío sobre el mundo; como afirma Franco Rella (El silencio 36): "contra él se elevan ahora las razones de la pluralidad de lo real" poniendo en cuestión el dominio de sí mismo y del mundo en la idea.

“¿Puede significar algo/ una vida librada al puro accidente?” se pregunta en Principios de incertidumbre (306) y como un "teólogo fracasado ante la única realidad posible/ con su correspondiente dolor de cabeza al anochecer" (380) Giannuzzi insiste en intentar reponer un "significado" a la visión que, desde la ventana, "sólo ofrece alternativas de una apariencia dislocada/ hecha de fragmentos trémulos, colores dudosos/ y un sufrimiento de cosa oscuramente mezclada consigo misma" (380). La imposibilidad de dar una respuesta certera ante lo incierto, de construir un pensamiento que sintetice y suture el "malentendido", así como también la fisura que traza la relación del poeta consigo mismo y su tiempo, parece atentar, en principio, contra la tarea de ser contemporáneo del mundo. Mientras a modo de "Aproximación a una ontología" personal insista la pregunta anacrónica por el qué del sentido, su respuesta no podrá ser alcanzada y el yo quedará reducido a un "cero" "ciego" incapaz de percibir otra cosa que su propia imposibilidad:

Pero qué es esta descomunal presencia, este animal espeso, esta masa pesada y sospechosa

donde el pequeño yo se pierde hasta volverse cero y ciego, girando entre millones

que quieren comer y entender un poco como él.

Qué es este abundante tejido, esta cosa maciza, empecinada, que el yo nervioso quiere penetrar como un taladro

para ver qué sucede, si hay alguna

explicación detrás, un lenguaje articulado, alguna forma claramente organizada.

[...]

Pero qué es esto, qué es lo que todo esto está tratando de decir. (601)

Ya sin orden capaz de dar cuenta del estatuto caótico del presente, sin "taladro" con que penetrar lo dado en busca de una "explicación detrás", el poeta solo 
percibe "ronroneos discontinuos", intermitencias disonantes, fragmentos arrancados de su contexto. Y, sin embargo, es allí mismo, en lo fragmentario del presente y en lo precario de la contradicción de un pensamiento que intenta medirse con eso que hay, que es posible proponer otra práxis del sentido. Porque si la pérdida del orden de la razón parece abismar en la nada la búsqueda de sentido y oponer tan solo un pensamiento negativo que afirma la muerte como único modo de apropiación plena (insensata), no parece ser esa la opción elegida por Giannuzzi. Incluso en los numerosos lugares donde la muerte aparece tematizada, ésta no funciona más que como el límite extremo, crítico, desde donde esta poética se escribe indicando que la experiencia de la crisis no culmina en el silencio, sino que insiste en el intento de dar razón en la fisura. Como dijera Kamenszain, "de cara a la crisis instala Giannuzzi su trabajo de investigación" (Cit. en Fondebrider 80) y comienza su búsqueda: aquella que intenta encontrar, más allá de la relación luctuosa con lo perdido, otro modo de experiencia, otra medida del lenguaje capaz de afirmar una relación con el mundo en la precariedad y en la imposibilidad de decirlo todo. Otra relación que, como veremos, no optará ante la crisis de la razón por oponerle su otro: ni el exceso de la locura ("fue la razón/ quien cegó sus propias ventanas. Pero tampoco/ encontró en el delirio conclusión alguna" (Giannuzzi 459)), ni la ruptura vanguardista con la lengua, ni la muerte como gesto pleno.

Allí donde el fin del mundo del sentido y, con él, el desmoronamiento del sujeto del saber clásico "ha abierto el espacio de la precariedad: el tiempo de la caducidad y del precipitarse de todas las cosas y de las palabras en el abismo de la crisis, de la falta de fundamentos" (Rella, El silencio 73), se tratará de recomenzar otro uso de las ruinas de la materia y la lengua, de trabajar en la contradicción de lo real sabiendo, como dijera Nancy, que el mundo no tiene sentido pero es el sentido. Quizás por eso en el dictum de su escritura que insiste en trazar la oscuridad de todo esto, algo se afirma pese a todo y pese al Todo y es allí en donde se expone una potencia de recomienzo: modificar la mirada del Todo, no ceder ni a la oscuridad, ni a las luces de la razón, ni a las del espectáculo.

Porque si un primer gesto político de su escritura se afirma en el intento de oponer otra imagen de la época, de exponer en su escritura toda la violencia de este tiempo que oculta su crisis, dicha imagen corre también el riesgo de volverse (para el poeta y para los lectores) una mera representación espectacular de la catástrofe continua e inmodificable que acaba por hurtar 
toda posibilidad de uso del tiempo, toda apropiación práctica de la historia en el estupor de la contemplación pasiva del derrumbe.

Sin embargo, el poema "Contemporáneo" otorga pistas para pensar un modo de interrumpir esta representación. Porque si bien la escritura insiste en afirmar que "hemos perdido el tiempo", hacia el final expone también la posibilidad de pensar otro modo de relación entre el pensamiento y su época. Posibilidad que surge allí donde el lenguaje de la poesía desune las imágenes del ocaso, espacia la continuidad del tiempo del horror y del fracaso para pensar, en esa suspensión, en esa impertenencia e impertinencia del tiempo, una época (“epokhé que significa 'suspenso' en griego" (Nancy, La comunidad 115)), valga la redundancia, que suspenda la época misma. En Giannuzzi es solo cuando se suspende el intento de dar razón, y se goza del indulto del mundo que ya no demanda sentido alguno de nosotros, que puede haber tiempo y espacio para recomenzar lo contemporáneo. Porque es solo cuando se interrumpe esa imagen del tiempo como sucesión homogénea de presentes que perpetúan el error que Giannuzzi traza un espaciamiento en el que es posible abrir el tiempo para que un nosotros en común tenga lugar:
Ahora comprendo que he sido un imbécil al suponer que el mundo
tal como fue traído hasta aquí por la historia, empujando batallas, dinastías y sangre podría sostener un pensamiento hasta el sepulcro.
Pero la lluvia de anoche en el sueño de mi hija cayendo en los cabellos de tres de sus pequeñas amigas, que incesantes giraban sin explicar su danza, hizo detener en ese espacio el conocimiento de mis años, el mecanismo exacto de una reflexión que duraba lo que mi edad contra la muerte. Ahora contemplo largamente esas imágenes como una bestia que se ha vuelto de pronto razonable [...]. (86)

En esa imagen que expone el gesto detenido de una danza que excede cualquier significación dada, es posible divisar otra praxis del sentido: suspender la interrogación por el qué, pasar de la búsqueda del tener sentido del mundo a la afirmación sin más de eso que ya es el sentido. Una nueva praxis que ya 
no nos sitúa como espectadores pasivos de un orden abstracto, como meros "resultados incompletos de fallas/y malentendidos antiguos".

Son numerosos, en este sentido, los poemas que impugnan en su escritura su propia visión catastrófica y continua. En Nuestros días mortales leemos: "¿Acaso, somos aquí pastores/ de equivocados actos, de humillantes maneras/ que no hallan razón ni sosiego? No: lo erróneo/ es esa visión gastada que busca la palabra exacta/ antes de aventurar las manos" (22). Y en el poema "Una llama es América" el poeta increpa el anonadamiento del pensamiento diciendo:

De manera que basta, pensadores oblicuos, a callar de una vez, invitados están a la mesa de todos. ¿Les faltan dioses? ¿Tienen poco sabor las uvas más recientes del mundo? ¿Es vacía y extraña la razón de sentarse y comer y estar juntos y marcharse después cada uno a su rostro? Pero, miren, a nadie interesa la ruina de indagar en sus actos sino callar y arder construyendo lo suyo. (47-48)

Ante la constatación de que es el intento mismo de comprensión y de síntesis el que conlleva al anonadamiento del sentido, y que es la imagen espectacularizada la que perpetúa el desprecio de lo existente, la escritura impugna su propia "terrible imaginación [que] no se da tregua/ para gobernar este derrumbe" (121). Es cuando se suspende la búsqueda melancólica de un sentido directriz, que "Uno comprueba entonces/ sin júbilo y sin pena, pero sí/ con un poco de paz bajo la frente/ que el lugar del sentido está en el centro/ de lo que somos, una/ especie de retorno a la primera/ interrogación, una/ dulcísima vuelta hacia el asombro" (72).

Es interrumpiendo la desideración y el lamento, que este poeta puede otorgarle otra eficacia a las palabras y a la mirada de lo común: devolverle la potencia de ser un medio que inscriba y propicie una experiencia práctica del sentido cualitativo, singular e inequivalente de la existencia y sus relaciones. Ante esta constatación, este "teólogo fracasado" vuelve su mirada al mundo como extensión a la vez devastada y disponible, para afirmar una nueva potencia poética aunque precaria: ya no dar razón del mundo sino hacer del mundo y de la existencia una razón que se sostiene por sí misma. Como dijera Monteleone (Cit. en Fondebrider 113), al modificar la mirada, Giannuzzi no encuentra "divinidad allí, sino una 'religión voluptuosa', la 
consagración suprema de la materia en su acontecer, más allá del lenguaje y allende la conciencia" y puede afirmar, entonces: "Sentí la existencia en fermentación/ cuando concebí entonces/ una noción de Dios/ simplificada, ambiciosa, provisoria:/ Dios era todo lo que veía, / un sistema, un principio absoluto de no vacío" (585).

$\mathrm{Su}$ apuesta por el recomenzar se jugará, entonces, en dos movimientos conjuntos: modificar la mirada, proponer a partir de ella otro modo de pensamiento. Un pensamiento situado más allá del "conocimiento" que pretende "vaciar la oscuridad" llenándola de "respuestas", más allá de las conclusiones que pretenden otorgar "precisas normas para agonizar mejor" (452), más allá, en suma, de las opciones dicotómicas entre pesimismo y optimismo, entre la palabra soberana y dadora de sentido y el silencio: otro modo de hacer sentido, en suma, que encuentra en la interrupción la ocasión de sintetizar la oportunidad perdida. Quizás, esta nueva praxis del sentido, del pensamiento y de la escritura sobrevendrá, como afirma nuevamente Nancy (El sentido 24), de la

exploración del espacio que nos es común a todos, que hace nuestra comunidad: aquel que corresponde a la generalidad más extensa del sentido, a la vez como una extensión distendida, devastada -el 'desierto que crece'- y como una extensión ampliamente abierta, disponible, y de la que nosotros resentimos algo así como una urgencia, algo así como una necesidad o un imperativo. Este espacio común es infinitamente delgado, no es más que el límite que separa y mezcla a la vez la insignificancia conseguida por pulverización de las significaciones, y la no-significancia o la archi-significancia que reencuentra la exigencia de ser-en-el-mundo.

III

Pese al gesto que insiste en trazar la separación entre el tiempo catastrófico de la historia y el de la vida de cada existencia particular, su poética no ha dejado de medirse con la tarea de hacer de la escritura el medio en donde la existencia no escindida devenga a la vez sensible e inteligible por el hallazgo de una imagen retenida y continuada en el poema. Asumiéndose como un "poeta incierto", Giannuzzi fue capaz de encontrar, aún en los restos, materia y forma para seguir escribiendo, para seguir ensayando un nuevo uso de las palabras, otra exploración del mundo, de ese territorio en donde la insignificancia se codea con la archisignificancia de lo que hay de más próximo y compartido: 


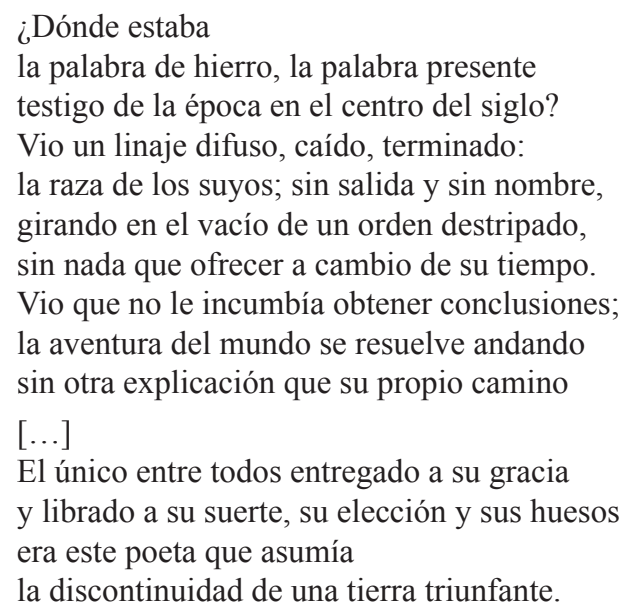

Asumir la discontinuidad de esta tierra triunfante para hacer de ella el sentido reclama, decíamos, otro uso de las palabras. "¿Quién pagará por esto sino un arte en llamas/ no saciado en su tortura, poema sonoro/vuelto una afirmación de estrellas/ en el seno de esta especie desastrosa?" (580), se pregunta en ¿Hay alguien ahí? Y, al mismo tiempo, en Las condiciones de la época afirma que, si de lo que se trata, en poesía, es de aislar una belleza, esto no puede realizarse apartando la crueldad y el martirio como una "falla", "como un paso en falso del mundo" (143). Es, en cambio, en este mundo y en esta historia que hay cosas, objetos, restos que aún en la catástrofe "se empeñan en dar música", en seguir "resonando en medio de la masacre" (143) y habrá que prestarles oído y una mirada a su medida.

En este punto su poética, como afirma Mattoni (142), coincide con el aserto de Baudelaire: “"no tenemos derecho a despreciar el presente’ decía. Eso sería aceptar la condena de la época”. El presente, dirá Giannuzzi, debe ser acogido por un lenguaje renovado capaz de atender a lo particular, aunque sin elevar románticamente "lo fugaz, el instante a la altura de lo intemporal" (Mattoni 142). Y es la escritura el único medio que tiene la potencia de acoger, simultáneamente, lo que hay de oscuro y de luminoso en todo esto. Quizás por eso en sus poemas son las mismas figuras que marcan una oscuridad inapelable, las que abren una tregua, aunque sea precaria, a partir de la cual intentar entablar otra relación con nuestro mundo. Una cosa cualquiera, "Café y manzanas", puede ser ocasión también para anunciar, desde el asombro que otorga una austera felicidad, que "el mundo se ha vuelto hospitalario,/ como 
una tregua en medio de la historia./ Las manzanas despiden un resplandor amarillo,/ el café entrega su humo íntimo" (Giannuzzi 148).

Como afirma Rella (Desde el exilio 10), "felicidad y horror, vergüenza y exaltación, se unen indiscerniblemente en un estado de inexorable desnudez. Este lugar es la escritura". En la de Giannuzzi, la certeza inapelable de las ruinas de un mundo convive con el asombro que provocan las imágenes de la singularidad de lo existente que trazan su fuerza de exposición testimoniando, con su mero estar ahí, que la vida empieza "en todo momento, desde cualquier/ conclusión,/ rabiando, empujando, sabiendo/ que la posibilidad infinita de la muerte/ tiene que estrellarse contra la suya" (94).

Porque si bien la muerte es eso inevitable que sucede siempre (aunque también siempre después) la poesía de Giannuzzi afirma insistentemente que sin embargo hay. Que es allí donde se suspende el tiempo lineal y progresivo pero también el tiempo lineal y regresivo (la experiencia continua del tiempo, en suma, como mera pérdida y caducidad irredimible), que se abre la ocasión de trazar otro pensamiento, otra mirada, otra relación entre las palabras y lo dado. Con una "vitalidad desesperada" (Barthes 60), en su poética, como sugiere Picardo (Cit. en Fondebrider 94-95), "entre la decrepitud y el dolor de la historia argentina, flota a salvo la isla de una mirada que es pensamiento. Y de un pensamiento que intenta volverse mirada". Más allá de las conclusiones de la razón y del espectáculo, más allá de la técnica monetaria y sus cálculos maliciosos, este poeta goza de la proximidad de lo que hay rendido a la consideración incalculable de su singularidad y finitud:

Felicidad del arroyo que desciende entre las piedras cuando mi pie desnudo sumerjo en su lenguaje.

Un proceso de la muerte que no puedo desdeñar mientras en la ciudad, bajo este fragmento de verano reina una inquietud desconocida.

Mi profunda culpabilidad humana infecciona el agua. Debo comprender de una vez por todas y aquí parece el sitio adecuado, el estimulante arroyo con árboles y la gracia de la creación en la mañana. Recuerdo, años que ya no cuento, apostando a la justicia de un alimento verdadero para todos, confiando en la historia y la salida del sol o en el peor de los casos el encuentro de un balazo en la noche o la personal angina de pecho después de los cincuenta. 


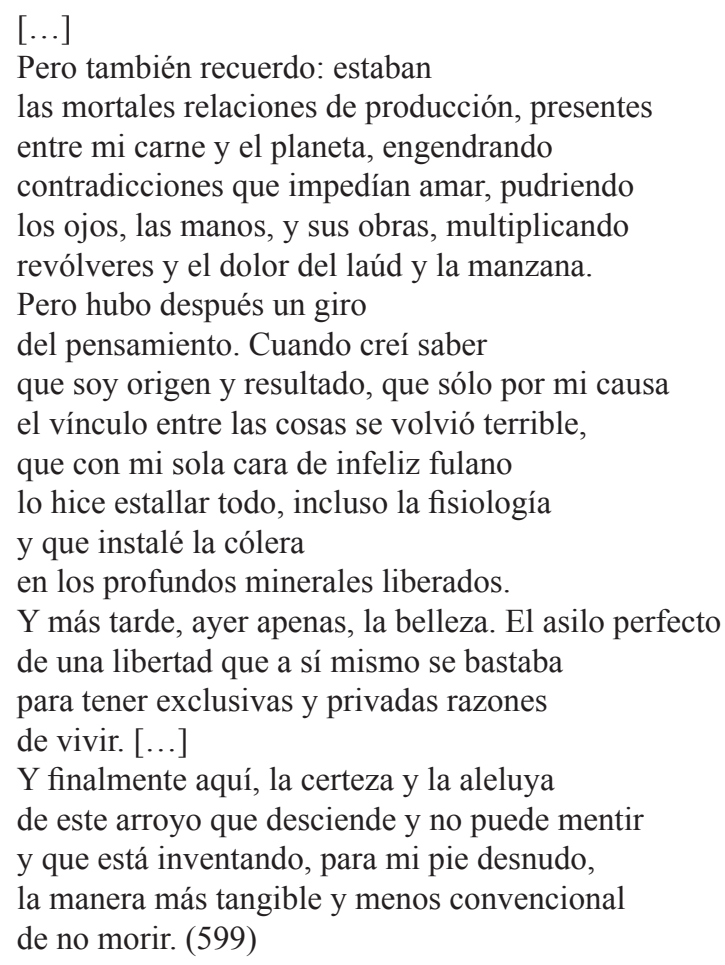

Es en el encuentro repentino, próximo con lo que hay, que Giannuzzi puede escapar de la tiranía de sí mismo y afirmar allí una oportunidad: “creo en todo esto;/ [...]/ Hay pan, frutas y vino entre nosotros/ y excelentes razones para vivir" (186). Hay el humor, la ironía que aliviana. Hay también la potencia de los cuerpos que hacen posible pensar de otra manera ese fruto extraño y perecedero que tan a menudo en su escritura devuelve, sintomático, las marcas de las crisis del tiempo. Hay también lo gestado, "leda, mi hija pequeña" (2014: 30-31) y las preguntas que con ella insisten confirmando nuestra relación con el mundo, incluso allí donde la respuesta no podrá ser sino la vastedad que coincide con el mundo mismo. Hay el amor que otorga otra posibilidad al estar desnudos en la noche. Hay un tú que insiste como destinación incierta, al menos como espera: "Tu sospecha de que la verdad no se agota en la historia/ con el rostro del martirio solamente:/ ni con la tramposa dialéctica de la culpa,/ será el comienzo de algo más claro y más despierto." (Giannuzzi 102). Hay los poetas y narradores que escribieron, que aún se leen y se invocan como en aquel "Llamando a Rimbaud" (558) 
en el que el poeta lo invita "a bailar un rock con los muchachos" diciendo: "Venite a darles respiración sublevada/ contra el viejo desierto,/ ayudalos a robar el fuego, a reventar el Super Shopping/ y expulsar del planeta a sus altos funcionarios/ con exactas escupidas/ en la plena mentira de sus ojos".

Hay la obstinación y la fuerza del poema mismo, que obliga a "El poeta Standard" (604) a saltar de la cama para escribir aquello que ya no puede retener y poner un huevo en el tiempo:

El poeta pequeño se despierta en estado de alerta: las palabras que amontonó en la noche se le hacen imposibles de retener y corre a sentarse a la mesa al amanecer.

Así que a lo largo del día suelta incesante imágenes continuas, olvida el desayuno y otras necesidades menores del destino. En resumen, un frenesí creador pero de resultado dudoso. ¿Pero quién podría decirlo, diseñar lo perdurable, medir la exacta distancia entre el entusiasmo y su obra? ¿Por qué el día habría de quedar perdido?

Lo que importa es poner huevos no en eternidad sino en el tiempo: allí donde los errores, rotas las cáscaras, deben rendir cuentas a la luz.

Hay también animales e insectos que confirman que aquello que no se comprende en absoluto custodia, sin embargo, su propio sentido sensato. Hay flores, "Violetas en el muro" con "olor a planeta recién nacido" (515), una "Dalia inclinada hacia mi ventana" (406) ante la cual el poeta celebra "que no seas/ una efusión de mi cabeza calcinada/ sino la aventura de una vida individual/ que me busca en la tarde lluviosa" y el deseo finalmente afirmado como "Invitación a la dalia" de "que tengamos comunión y bodas/ con esa certidumbre vegetal" (541). Y están también las "Anémonas de Matisse" ante las cuales el poeta afirma que "amar el mundo, su abundante presente,/ es obtener más luz:/esta celebración de la apariencia/ que sin embargo se sostiene hasta el fin" (363). 
En esta celebración del mundo, del abundante presente, incluso las cosas, desechos, basuras y demás objetos manufacturados que antes mostraban solo su costado anonadante encuentran ahora, en la mezcla, la posibilidad de afirmar una "forma arrebatada a lo fortuito":
en aquella derrota humana de las cosas, en los desperdicios mojados podían descubrirse figuras creadas a partir de la mezcla, diseños irreales arrebatados a lo fortuito: y entre gotas de lluvia y aceite quemado una intención de belleza y de formas cumplidas bajo la maloliente oscuridad. (450)

Allí, entonces, la potencia estética de la poesía encuentra modos de trazar relaciones entre lo heterogéneo, de dar a ver algo más que una mera acumulación de restos. En ese gesto, la falta de sentido expone también su reverso: que "no hay sentido dado en parte alguna que pueda hacer tolerar lo intolerable y que no hay más no-sentido en virtud del cual descalificar o anular la existencia" (Nancy, El sentido 125).

Lo que se afirma entonces es el hay del mundo, pero sobre todo el hay de la poesía, de la escritura y de su potencia para exponer la oscuridad insensata de nuestra época e interrumpirla. Es la escritura la que puede afirmar un yo frustrado, impotente ante una realidad catastrófica que no logra comprender $\mathrm{y}$, al mismo tiempo, suspender su pathos, su sed infinita de significado y abrir en el poema una imagen, un vacío, un umbral de reposo donde hay tiempo y espacio para todo. Es su escritura singular, en suma, la que puede recomenzar el sentido del mundo, mirarlo de otro modo, abrir un mundo allí donde solo se percibía un gran basural, un espacio devastado y clausurado. Porque como afirma Monteleone (Cit. en Fondebrider 298): “el mundo no es poético en sí mismo, aunque manifieste la gracia de una vitalidad sin límites: lo es cuando el lenguaje manifiesta su orden a partir de una límpida percepción, en la cual la certeza de la muerte se suspende en el acto continuado de su aparición". Allí donde la Historia ha igualado a todas las cosas y los seres en el ultraje y el martirio que impone la violencia y el sinsentido, la poética de Giannuzzi encuentra la posibilidad de multiplicar La Historia en historias suspendiendo la mirada que aún espera la gran revolución para atender a aquellas pequeñas mutaciones que otorgan ocasión de afirmar una nueva fe, ahora depositada en el poema mismo que sin embargo se escribe. 
A lo largo de estas páginas hemos recorrido los lugares donde la escritura poética de Giannuzzi expone el devenir inmundo del mundo, indicando, al mismo tiempo, la necesidad de imaginar otros modos de valoración de lo que hay. Donde la pluralidad de lo real proyecta sobre el pensamiento poético una fuerza contradictoria que resiste todo intento de ser subsumida en una unidad significante, su escritura insiste en la tarea de encontrar modos de afirmar una relación precaria con los restos. Una relación que parte y llega a un mismo "principio de incertidumbre", que no va de la duda a la certeza, de la destrucción a la construcción, sino que trabaja allí, en lo precario, recomenzando en sus diferencias.

Abrir el tiempo, hacer espacio en su discurrir incesante para volver sensible una imagen no espectacular del mundo, ensayar una y otra vez una mirada inequivalente allí donde la técnica y el capital han acabado por convertir toda materia y toda existencia en un objeto de propiedad, uso, consumo fetichizado o destrucción, esa parece ser su apuesta. Y es, decíamos, en y por la escritura que Giannuzzi se hace tiempo y se hace de su tiempo para entregarnos, a cambio, otra imagen de aquello que sucede: una imagen que nos regala otro modo de vernos a nosotros, de afirmar un común en este mundo que toca su fin. Es impugnando la escritura espectacular que siempre entrega el hecho sin su posibilidad, que circula imágenes y acontecimientos separados de la potencia de sus hacedores, e interrumpiendo también su propia escritura oscuramente totalizante, que el poeta se vuelve hacia lo que hay para dar visibilidad, a esos pequeños sucesos que devuelven una experiencia práctica de la historicidad a los cualquiera que son los encargados de hacerla. Gesto poético que, como señala Monteleone (Cit. en Fondebrider 299), se sostiene no

en una figuración del instante o en un presente extático, sino en una acción que se desarrolla y que el gerundio expresaría adecuadamente. La poesía no corresponde al orden de los objetos que se han visto, sino de lo que se está viendo. Pero, al mismo tiempo, ese orden se duplica en aquello que se está escribiendo, [lo que] significa también que el arte -la poesía, la música, la pintura- es capaz de establecer una especie de acción durativa respecto de 'nuestros días mortales'.

Así, si la poesía argentina contemporánea todavía se mide en relación con su obra, no es ya, entendemos, solo por el mero descubrimiento de una forma que supo hacer escuela sino sobre todo por la afirmación ético-política que ella 
expone y cuyas consecuencias siguen siendo exploradas por el movimiento de lo que todavía se escribe en nuestros días. Y si su escritura se sostiene de principio a fin en un "mismo tono", si Chejfec (10) supo ver en su "coloratura regular" un "efecto cuaderno" o una suerte de "diario", es porque el trabajo, la tarea de hacer sentido en y con lo precario es interminable, solo capaz de ser interrumpida por la muerte.

Como Kafka (Rella, El silencio 196), Giannuzzi supo "que la lógica es inquebrantable pero no resiste ante un hombre que quiere vivir", ante quien puede desear la contradicción, avizorar una inquebrantable oscuridad del todo y saber al mismo tiempo que la misma puede ser desunida, interrumpida, espaciada, desobrada para afirmar allí el valor inequivalente del hay, de una existencia singular, de un encuentro, de un mundo, en suma. Porque como dijera Nancy (El arte hoy 67),

es del valor único e inconmensurable de cada existencia que un mundo está hecho, no de la sumisión a alguna medida supuestamente dada desde otro lugar que de ese singular de los existentes. Esto puede decirse aún de otra manera: un mundo no está regido por 'valores' que flotan sobre él, sino por las evaluaciones o las valorizaciones, las puestas en valor, en suma, las afirmaciones de todos y cada uno.

Es cuando el pensamiento y la escritura trazan en una imagen la apertura que impide que lo mirado se cierre sobre sí mismo como un bien apropiable o que se fugue sin más hacia el fin último al cual sus representaciones lo ligaban, que es posible afirmar otra relación con los restos. Escribiendo el encuentro con lo que hay por fuera de toda equivalencia lo que se expone es ese instante de co-presencia en el que lo que vale es el tener lugar del ser en cuanto tal. Lo que se visibiliza, entonces, es un mundo como aquello en "donde todo está apud todo: todo está cerca de todo, todo tiene lugar, pero nada hace un Todo. Y este 'no hacer un Todo' es justamente lo que hace ser o deja ser ... ¡todo!” (Nancy, El arte hoy 75).

\section{BIBLIOGRAFÍA}

Agamben, Giorgio. Desnudez. Trad. Mercedes, Ruvituso; Teresa, D’Meza. Buenos Aires: Adriana Hidalgo, 2011.

Infancia e Historia. Trad. Silvio, Mattoni. Buenos Aires: Adriana Hidalgo, 2007.

Barthes, Roland. Lo Neutro. Trad. Patricia, Willson. Buenos Aires: Siglo XXI, 2004. 
Chejfec, Sergio. Sobre Giannuzzi. Buenos Aires: Bajo la luna, 2010.

Didi-Huberman, Georges. "Salir del plano". Hacer. Ensayos sobre el recomenzar. Franca Maccioni; Javier Martínez Ramacciotti, comps. Trad. Franca Maccioni. Buenos Aires: Teseo, 2015.

Fondebrider, Jorge, comp. Giannuzzi. Reseñas, artículos y trabajos académicos sobre su obra. Buenos Aires: Ediciones del Dock, 2010.

Giannuzzi, Joaquín. Obra completa. Buenos Aires, Del Dock, 2014.

Maccioni, Franca. "Pensar el fin hasta el fin y habitar sin medida. Hacia un comunismo de la inequivalencia". Revista Constelaciones 7 (2016): 594-601.

Masiello, Francine. "En los bordes del cráter (sobre la generación del noventa en Argentina)". Revista Cuadernos de Literatura 31 (2012): 79-104.

Mattoni, Silvio. El presente. Poesía argentina y otras lecturas. Córdoba: Alción, 2008.

Nancy, Jean-Luc. La comunidad inoperante. Trad. Juan M., Garrido Wainer. Santiago de Chile: Arces-Lom, 2000. L'Équivalence des catastrophes (Après Fukushima). París: Éditions Galilée, $2012^{4}$. El sentido del mundo. Trad. Jorge Casas. Buenos Aires: La Marca, 2003. El arte hoy. Trad. Carlos Pérez López; Daniel Álvaro. Buenos Aires: Prometeo, 2014.

Rancière, Jacques. Figuras de la historia. Trad. Cecilia González. Buenos Aires: Eterna Cadencia, 2013.

Rella, Franco. El silencio y las palabras. El pensamiento en tiempos de crisis. Trad. Andrea Fuentes Marcel. Barcelona: Paidós, 1992.

Desde el exilio. La creación artística como testimonio. Trad. Paula Fleisner. Buenos Aires: La cebra, 2010.

$4 \quad$ Las traducciones de las citas de este libro son nuestras. Las mismas han sido publicadas en Maccioni (2016). 